\title{
Personal, Social, Environmental: Future Orientation and Attitudes Mediate the Associations between Locus of Control and Pro-environmental Behavior
}

\author{
By Yocheved Yorkovsky* \& Leehu Zysberg ${ }^{\dagger}$
}

\begin{abstract}
This study tested a model in which pro-environmental attitudes mediate the association between personality traits (locus of control and future orientation) and pro-environmental behavior. Two hundred and thirty participants completed measures of the above concepts and provided information about demographic variables known to be associated with proenvironmental behavior. Path analysis supported a double mediation model in which future orientation and pro-environmental attitudes (in this order) mediate the association between locus of control and behavior. Of the demographic variables, only age was directly associated with behavior. The results are discussed in light of the theory and previous findings.
\end{abstract}

Keywords: future orientation, locus of control, mediation model, personality, pro-environmental behavior.

\section{Introduction}

Fears for the future of our planet rise with accumulating evidence of environmental and ecological hazards (e.g., Masson-Delmotte, Intergovernmental Panel on Climate Change et al. 2018). Heated debates develop around the importance and validity of the environmental plea for action (Nunez 2019). Against this backdrop, it becomes more and more important to examine factors that differentiate individuals in how they perceive, appraise, and act upon the issue of caring for our environment. In an era when facts and figures are more available than ever but more controversial and difficult to process, it is key that we understand underlying resources, predispositions, and individual-level variables that may account for how individuals (and groups) relate to these data and translate them (if at all) into action (or lack of it).

One of the most prominent theoretical frameworks that account for factors associated with behavior and behavior modification is the Theory of Reasoned Action (TRA; Madden et al. 1992). This theory provides an insight into individual level processes, pertaining to personality pre-dispositions, attitudes and cognitive perceptions, and how they shape behavior. This classic framework offers a basic understanding of how attitudes; representing individuals' emotional, cognitive and behavioral reactions to an object, behavioral beliefs; a concept representing individuals' motives for behavior,

\footnotetext{
* Chair of the Green Council and Health Committee, Gordon College of Education, Israel.

${ }^{\dagger}$ Associate Professor, Gordon College of Education, Israel.
} 
and peoples' evaluation of the outcomes of their intentions, elicit behavior. We therefore use this model as our overarching theoretical umbrella associating individual level factors and pro-environmental behavior.

Existing research, stretching back to the 1970s, has addressed the question of which, and to what extent, personality traits, attitudes, perceptions and other individual level characteristics are associated with pro-environmental perceptions and actions (e.g., Arbuthnot 1977). While existing research identifies anecdotal factors associated with pro-environmental behavior (PEB), a theory supported comprehensive model that identifies factors and processes associated with PEB is still lacking. This study attempts a step in this direction by identifying individual factors associated with pro-environmental attitudes which in turn associate with PEB. We thus offer a process model of PEB.

\section{Literature Review}

Attempts to identify personality profiles associated with pro-environmental attitudes have shown inconsistent results (briefly reviewed later in this paper). More interesting perhaps is the search for individual-level elements and concepts that may account for the extent to which individuals commit to proenvironmental behavior. Of special interest is identifying those personal-level concepts that are not just given but that are also at least somewhat amenable to change, thus pointing out potential paths for future interventions and education programs. This study, thus, proposes and tests a multitiered model of personal factors and the routes by which they may be associated with pro-environmental behavior (PEB).

Existing studies of personality and PEB focus on specific personality traits such as extraversion, sincerity (Pettus and Giles 1987), higher self-esteem, emotional connection to nature, and prosocial predisposition (Markowitz Goldberg Ashton and Lee, 2012). Numerous models and individual traits have been studied, and most have shown sporadic and often inconsistent evidence of links with PEB patterns. What concept is most relevant in accounting for such behavior? Examining the essence of PEB may present a potential answer: this behavior often involves accepting certain levels of frustration or inconvenience for the sake of future benefit (Kaiser and Byrka 2011). Consideration of future consequences of behavior emerges as key to understanding such behaviors, since it affords individuals the choice between immediate satisfaction and acting to gain benefit in the far future (e.g., Deci and Ryan 2004, Strathman et al. 1994). Studies have identified the concept of future orientation (FO) as the individual predisposition to bring future outcomes into current considerations of one's actions (Seginer 2009). Although studies have already established associations between FO and a broad range of behaviors (e.g., saving money, avoiding risky behaviors), only recently has evidence been published linking FO with pro-environmental perceptions and attitudes; however, the evidence was somewhat inconclusive for actual behavior (Carmi 2013).

Another personality-related concept that holds promise in this direction is that of locus of control (LOC; see Ajzen 2002). This concept relates to the 
tendency of individuals to attribute control to either themselves or external sources (luck, God, fate, etc.) and the extent to which they feel they can control and navigate events in their lives. The concept emerged about three decades ago as a pivotal factor in accounting for behavior-change interventions, and in facilitating goal-oriented behavior (e.g., Ajzen and Madden 1986).

Both LOC and FO emerge as promising personality-related concepts in the context of PEB patterns; yet, to better formulate the shift from internal, individual predispositions to actual behavior, we need to address another missing link: PEAs.

Attitude is a concept representing the individual's tendency to react emotionally and cognitively and to develop a certain behavioral default toward a given object or idea (Ajzen and Fishbein 2005). In many contexts, attitudes are considered a potential for behavior toward a certain target object, person, or concept. In other words, many believe that understanding attitudes is pivotal to understanding behavior and modifying attitudes, and may often result in behavior modification (Fazio 1986).

Based on the above ideas, and using the framework of TRA, we propose a chain of associations leading from personality characteristics to actual behavior in the field of environmental conservation (Figure 1): characteristics representing a sense of control over oneself and one's environment, alongside the tendency to postpone immediate gratification for the benefit of future outcomes, shape positive attitudes toward environmental issues, and thus lead to PEB. We therefore present and test a model in which LOC and FO are associated with PEBs via the mediation of PEAs. We do so while controlling for demographic and background factors associated in the literature with PEAs: gender, age, religion and religiosity, and education level (Markowitz et al. 2012).

Figure 1. The Study Model

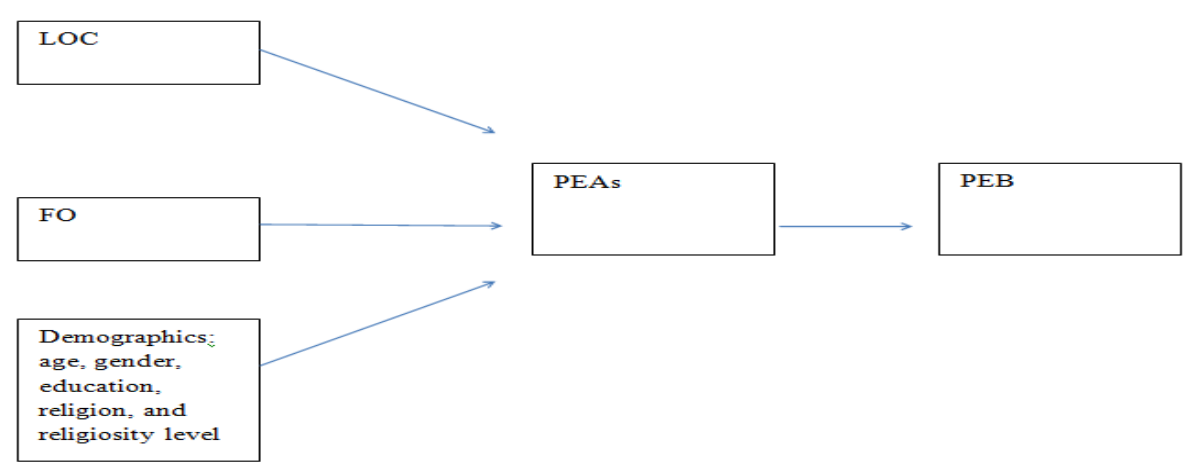

LOC $=$ locus of control $; \mathrm{FO}=$ future orientation; PEAs = pro-environmental attitudes; $\mathrm{PEB}=$ pro-environmental behavior.

We hereby briefly review the classic literature on each of the model's components, from the final outcomes backwards to follow the proposed process: 


\section{Pro-environmental Behavior}

PEB was defined as behavior that seeks to minimize the negative impact of one's actions on the natural world (e.g., minimizing resource and energy consumption, using nontoxic substances, reducing waste production; Kollmuss and Agyeman 2002). Significant environmental behaviors were defined as those undertaken to change the environment (Stern 2000). PEA can be viewed in the context of change: a change in one's own lifestyle, in one's school, in one's local community, or in global society in a manner that allows better conservation of resources and a smaller environmental footprint (Jensen 2002). Three factors in self-reported behaviors and behavioral intentions were revealed: consumer behavior (e.g., buying organic products, avoiding purchases from companies that harm the environment), environmental citizenship (e.g., voting, writing to government officials), and policy support, expressed as a willingness to sacrifice economically to protect the environment (e.g., by paying higher taxes or prices; Stern 2000). Courtenay-Hall and Rogers (2002) distinguished between direct environmental actions, such as recycling, driving less, and buying organic food, and indirect environmental actions, such as donating money, political activism, educational outreach, and environmental writing. This suggests that PEB varies not only in its nature but also in its magnitude: Finger (1994) noted three levels of PEA: standard environmental behavior (doing at least one of the following: recycling, using public transportation, etc., and trying to learn more about the environment), limited activism (doing the above plus at least one of the following: voting for candidates who are committed to the environment, trying to inform others, signing petitions in favor of environmental protection, and engaging locally to protect the environment), and protest behavior (doing the above plus at least one of the following: sometimes engaging at a local level, opposing projects that destroy the environment, and participating in public demonstrations for the environment).

\section{Pro-environmental Attitudes}

Environmental attitude (EA) is defined as a psychological tendency that is expressed by evaluating the natural environment with some degree of favor or disfavor (Milfont 2007). The traditional model of EA structure has three components: cognitive, affective, and behavioral (Cottrell 2003). The relationship between these components is complex and not necessarily linear. Newer approaches conceptualize attitudes as evaluative tendencies that can both be inferred from and have an influence on beliefs, affect, and behavior. These theories claim that cognition, affect, and behavior are the bases from which the general evaluative summary of a psychological object is derived, instead of being constituents of attitudes (Albarracín et al. 2005, Fabrigar et al. 2005, Milfont and Duckitt 2010).

Many researchers believe that understanding attitudes is pivotal to understanding behavior, and that modifying attitudes may often result in behavior modification (Fazio 1986). EA is a crucial construct in environmental 
psychology, a focus of most of that discipline's publications, and considered by most researchers to be a pivotal multidimensional construct in understanding environmental behavior and associated processes (Milfont and Duckitt 2010): it is widely believed that EA is an important predictor of PEB intention, which then accounts for actual PEB (Qian et al. 2019).

The main importance attributed to attitudes in general and to EAs in particular is their assumed associations with actual behavior. However, many individuals fail to translate their PEA into PEB. This inconsistency is widely called the "environmental attitude-behavior gap" (Redondo and Puelles 2017). Rajecki (1982) suggested that one of the reasons for this gap may be the method of measurement. He claimed that in order to find a high correlation between attitude and behavior, researchers must measure the attitude toward a particular behavior. More-narrowly targeted attitude measurements lead to higher correlations (Lehmann 1999). Ajzen and Fishbein (2005) claimed that attitudes do not determine behavior directly; rather, they influence behavioral intentions, which in turn shape behavior.

\section{Future Orientation}

FO is the individual predisposition to bring future outcomes into current considerations of one's actions (Seginer 2009). It can be defined in a socialcultural context as the degree to which individuals (or societies) engage in future-oriented behavior such as planning, investing in the future, and delaying gratification (Kluckhohn and Strodtbeck 1961). In personal psychological contexts, FO reflects the tendency of people to plan for and achieve future goals and to consider the long-term consequences of their behavior (Strathman et al. 1994, Zimbardo and Boyd 1999). It is a human trait that enables individuals to anticipate, make plans, organize future options, and choose an action that promises a significant but future reward, even if it involves paying a price now (Gjesme 1983).

A few studies showed that future-oriented individuals tend to care about the environment and are more likely to act pro-environmentally (Levy et al. 2018). For example, future-oriented individuals engage more in waterconservation practices (Corral-Verdugo et al. 2006), prefer commuting by public transportation (Joireman et al. 2004), and decrease their greenhouse gas emissions through mitigation behaviors (Corral-Verdugo et al. 2017). However, the current evidence is far from conclusive: other findings showed that highly future-oriented students did not express stronger PEAs, and that their willingness to sacrifice for the sake of the environment was significantly lower. They adopted PEBs only if doing so was to their personal benefit (Carmi 2013).

A meta-analysis study showed that the associations between time perspective (a concept often used for FO) and PEBs were higher than those for PEAs (Milfont et al. 2012). The findings indicate that FO or time perspective seems to play an important role in influencing individuals' attitudes and behaviors toward the environment. Thus, consideration of future consequences can be a significant predictor of PEBs and PEAs (Bruderer Enzler 2015). 


\section{Locus of Control}

The concept emerged about three decades ago as a pivotal factor in accounting for behavior-change interventions, and in facilitating goal-oriented behavior (e.g., Ajzen and Madden 1986). In the environmental behavior context, internal LOC represents the belief of individuals that they can bring about environmental changes through their personal behavior and that their actions with respect to the environment are therefore worthwhile. They typically perceive themselves as having control over their future and believe that outcomes are related to their actions (Cleveland et al. 2005). On the other hand, individuals who attribute change to external factors (e.g., not to personal behavior - external LOC) feel that their actions are insignificant, and that change can only be brought about by others (Hungerford and Volk 1990, Kollmuss and Agyeman 2002, McCarty and Shrum 2001).

People with an internal LOC are more likely to exhibit PEAs and PEBs (Bamberg and Möser 2007, Hines et al. 1987). For example, internal LOC is related positively to values related to the natural environment (Pe'er et al. 2007), to the importance that individuals attach to recycling (McCarty and Shrum 2001), and to consumers' willingness to pay for environmentally friendly products (Trivedi et al. 2015).

The relationship between LOC and PEB is not yet clear, even though it seems that internal LOC is a predictor of PEB (Allen and Ferrand 1999, Bamberg and Möser 2007, Cleveland et al. 2005). The relationship is probably not direct, and other variables, such as sympathy, may mediate it (Allen and Ferrand 1999).

\section{Demographics}

Studies point out a few demographic variables that are associated with the tendency to care more about the environment and adopt more positive attitudes in this venue. Two variables seem to emerge from the literature: Studies have suggested women tend to show higher environmental concern than men (Zelezny et al. 2000), and that people with higher levels of education show more positive attitudes toward environmental values (Felonneu and Becker 2008). These were therefore included in our model.

\section{Summary and Rationale}

There is agreement in the behavioral literature in general and on PEB in particular that attitudes play a pivotal role in shaping such behaviors. What shapes the relevant attitudes in such settings and regarding such subjects continues to be debated. We chose to focus on three types of predictors associated with PEAs: demographics - often mentioned in the literature as antecedents of PEA, especially gender and education level. We added religiosity and religion as potential demographic determinants of such attitudes, as these may be associated with individuals' perceptions of where the responsibility lies and who controls the fate of our natural resources. FO is a relatively recent addition to the concepts that are the focus of attention in 
environmental research. It may be of added value in our attempts to understand the dynamics behind attitude formation and change in the environmental context because it reflects the propensity of individuals to consider future events and the outcomes of their activities - an issue at the heart of the PEB conflict: am I willing to sacrifice my comfort now for the benefit of future generations? Finally, the veteran concept of LOC reflects the variance in the extent to which individuals feel that they can exert some control over their environment and their own world. Logic suggests that internal LOC is associated with more positive attitudes toward the environment and potential PEB.

We therefore posit that PEAs mediate the associations between demographics, FO, and LOC and PEB. Figure 1 summarizes the proposed model guiding this study.

\section{Method}

\section{Sample and Settings}

Two hundred thirty participants agreed to take "a survey of perceptions and attitudes about the world around us." They were recruited through various online social forums in Israel. Of the participants, $79 \%$ were women and $21 \%$ were men. Their mean age was 34.91 years $(S D=10.97)$. The majority were Jews (89\%), followed by Muslims (3.86\%) and Christians (2.29\%). The remaining $4.85 \%$ either identified as nondenominational or refused to answer. The greatest share of the sample had a bachelor's degree or equivalent $(39 \%)$, followed by a masters' degree (29\%), and about $30 \%$ who had a secondary school education. Two percent refused to report their education. While closely reflecting the ethnic makeup of Israeli society the sample was showed marked gender (more women than men) and education (more individuals with higher education than the general population) biases.

As noted in the literature review - these biases are typically associated with positive attitudes toward the environment - and as such would be expected to restrict the range of variable distribution in our sample. This means that chances are that any effect found in our sample may actually be an underrepresentation of the same effect in the population.

\section{Measures}

We used online self-report questionnaires; all are validated measures of the variables in our model.

\section{Pro-environmental Behavior}

Reported PEB was documented using 20 items about environment-related activities, with responses on a 5-point, Likert-type scale ranging from 1 (never) to 5 (almost always). The 20 items were constructed from six categories: resourceconserving actions with personal benefit (e.g.: "I recycle used bottles"), 
environmentally responsible consumerism (e.g.: "I purchase environmentally friendly products where poissible"), nature-related leisure activities (e.g.: "I take hikes in nature often"), recycling (e.g.: "I recycle used packaging materials"), citizenship ("I pick up discarded bottles or wrappings I find on the street and throw them in the garbage bin"), and environmental activism (e.g.: "I am an active member of a 'green organization"') (Yavetz et al. 2011). The original authors reported an internal reliability of .80 .

\section{Pro-environmental Attitudes}

PEAs were measured using a questionnaire developed by Yavetz et al. (2011), with an overall reliability coefficient of .86. Responses to the 24-item Likert-type scale questionnaire range from 1 (highly agree) to 5 (highly opposed). It includes five categories: the importance of the natural environment (e.g.: "It is man's right to take advantage of natural resources available to them" - reverse item), resource management policy (e.g.: "The government must encourage the application of alternative clean energy sources"), legislation and enforcement as a resource management tool (e.g.:"Factories that damage the environment must be heavily fined"), a sense of ability to influence environmental issues (e.g.: "even if I conserve resources and use recyclable products it is nothing in comparison to what's happening in the world" - reversed item), and the importance of environmental education (e.g.: "every college studnt should be required to take a course on environmental issues").

\section{Future Orientation}

FO was assessed using the Future Motivation subscale (Beal 2011), a 19-item questionnaire yielding a single total score that offers a brief and reliable measure of the concept. The measure showed good reliability coefficients ranging from .75 to .80 .

\section{Locus of Control}

LOC was assessed using the Locus of Control instrument, a simplified version of the Rotter questionnaire presented by Pettijohn (2004). The 20-item questionnaire contains statements with which respondents can either agree or disagree. The sum of the scored choices yields a single score representing internal LOC. The measure was chosen for its user-friendly structure compared with Rotter's original measure. The shorter scale showed high correlation with Rotter's original measure and acceptable reliability indices (Pettijoh et al. 2005). In our study it showed adequate reliability (.66).

\section{Demographics}

Participants were asked to report their age, gender, level of education, religious affiliation (a correlate of ethnicity in Israel), and religiosity level.

\section{Procedure}

After approval of the study by the authors' IRB, a call for participation was issued in online social media forums, with a link to the questionnaires that also 
included a brief informed-consent form. Data were gathered in a way that did not require individuals to expose their identity and thus were anonymized throughout the process.

\section{Data Analysis}

Preliminary descriptive statistics were calculated using IBM SPSS 24.0. The model-testing path analysis was conducted using ISM AMOS 19.0, which includes a test for direct and indirect effects.

\section{Results}

\section{Descriptive Statistics and Preliminary Analyses}

Before testing the proposed model, we examined the descriptive statistics and preliminary associations between the main variables in the model. Table 1 summarizes these analyses.

The results suggest reasonable-to-good reliability coefficients for the questionnaire-based scores. The distribution showed no ceiling or floor effect, and standard deviations were noted. The preliminary examination of the associations between the study variables did not necessarily support the proposed model: attitudes and behavior showed a positive correlation, and religiosity was negatively associated with environmental attitudes and behavior. LOC and FO also correlated with each other, as expected, but the expected correlations between FO, LOC, and environmental attitudes and behavior did not emerge in this preliminary analysis.

Table 1. Descriptive Statistics and Intercorrelations among the Study Variable $(N=230)$

\begin{tabular}{|l|c|c|c|c|c|c|c|}
\hline Variable & 1 & 2 & 3 & 4 & 5 & 6 & 7 \\
\hline 1. Gender & - & & & & & & \\
\hline 2. Age & .11 & - & & & & & \\
\hline 3. Religiosity & .08 & -.09 & - & & & & \\
\hline 4. LOC & .04 & .08 & -.05 & - & & & \\
\hline 5. FO & -.05 & -.03 & .00 & $.30^{* *}$ & - & & \\
\hline 6. PEB^ & .03 & $.32^{* *}$ & $-.23^{* *}$ & .05 & -.09 & - & \\
\hline 7. PEAs^ & .08 & $.29^{* *}$ & $-.21^{* *}$ & -.04 & -.10 & $.52^{*}$ & - \\
\hline Mean & $\mathrm{F}=79 \%$ & 34.91 & 1.49 & 14.96 & 3.67 & 2.84 & 1.66 \\
\hline$S D$ & $\begin{array}{c}\mathrm{M}=21 \\
\%\end{array}$ & 10.97 & .75 & 2.18 & .49 & .89 & .61 \\
\hline $\begin{array}{l}\text { Reliability } \\
\text { Cronbach's alpha }\end{array}$ & - & - & - & .66 & .74 & .72 & .84 \\
\hline
\end{tabular}

Note. ${ }^{\wedge}$ Scales are reversed (lower grades indicate higher endorsement of attitudes or behavior). $\mathrm{LOC}=$ locus of control; $\mathrm{FO}=$ future orientation; $\mathrm{PEB}=$ pro-environmental behavior; $\mathrm{PEAs}=$ pro-environmental attitudes.

$* p<.05 ; * * p<.01$. 
Model Testing

Path analysis was used to examine the model, and to test for the direct and indirect effects it suggested. This method allowed us to test a full, complex model without the danger of capitalization on chance (Wootton 1994). The analysis results are summarized in Figure 2 and Table 2. Whereas the original model was not supported by the data at the required level, a slightly modified model did show excellent fit with the data and is presented in the figure.

Figure 2. The Empirical Model

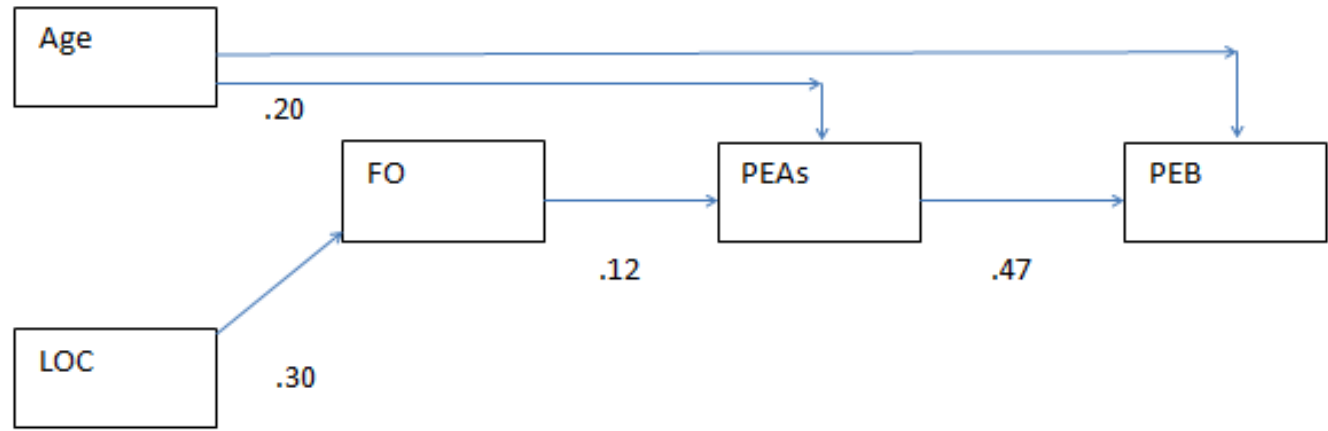

All marked path coefficients are significant at $p<.04$ or better. Nonsignificant paths and variables, as well as error terms, were omitted from the figure for ease of presentation LOC = locus of control; FO = future orientation; PEAs = pro-environmental attitudes; $\mathrm{PEB}=$ pro-environmental behavior. Goodness-of-fit indices: Chi-square $=1.88(\mathrm{df}=4) p>.75$; $\mathrm{CFI}=.99 ; \mathrm{NFI}=.98 ; \mathrm{RMSEA}=.01$.

Table 2. Summary of Indirect Effects

\begin{tabular}{|l|c|c|c|c|}
\hline Variable & LOC & FO & Age & PEA \\
\hline FO & .00 & .00 & .00 & .00 \\
\hline PEA & .03 & .00 & .00 & .00 \\
\hline PEB & .02 & .47 & .12 & .00 \\
\hline
\end{tabular}

Note. LOC = locus of control; FO = future orientation; PEB = pro-environmental behavior; PEAs $=$ pro-environmental attitudes.

$* p<.05 ; * * p<.01$.

The empirical model offers a surprise. Beyond revealing indirect associations between LOC, FO, and the outcome variables (which were not demonstrated through simple correlations), it provided some interesting insights into the nature of the associations found. The most surprising result is that LOC and FO were found to work at different levels, with LOC preceding the effect of FO in the chain of indirect effects. Second, most of the demographic variables, including religiosity (which showed some interesting association patterns at the simple-correlations stage), did not enter the empirical model, with the exception of age-which was positively associated with both PEA and PEB. Overall, the model supported the idea that both 
personality-driven variables and attitudes mediate the association between individual predispositions and PEB.

The potential implications of this model for theory, future research, and potential interventions are discussed next.

\section{Conclusion}

Understanding the antecedents of PEB grows increasingly important in both the educational and the general public contexts. Although many agree that environmental issues pose a pressing threat and challenge to the world's population (Volcovici 2019), relatively few express commitment to PEAs, and even fewer adopt a pro-environmental way or life-or, in the terms discussed here, show high levels of PEB. What may account for this gap? In this study we aimed to learn more about the implications of personal characteristics for PEAs and PEB and to reveal those that may play a significant role in the relationship between the two concepts. The model we presented and tested here suggests that certain demographics and personality aspects may play a role in the adopting of PEAs - and, as a result, in PEB. From the existing literature on PEAs we identified demographics such as age, gender, education level, and even religiosity, and from the literature on personality we identified both FO and LOC as potential factors associated with PEA. To our best knowledge, unlike in the present study, previous research did not examine LOC and FO simultaneously. Our empirical model focused on a narrower scope of concepts and variables: whereas for the demographic variables, only age was positively associated with both PEA and PEB, for the personality factors we found a serial mediation effect, which is slightly different from what we expected: FO and PEAs both serially mediated the association between LOC and PEB. This may mean that LOC allows for higher levels of FO, and that this in turn leads to the formation of more positive environmental attitudes. Those attitudes are eventually associated with PEB.

Although these results were not predicted by the original model, they make sense and fit the existing literature on LOC and FO (see, e.g., Ahlin and Antunes 2015, Stratham et al. 1994). However, this is the first time, to the best of our knowledge, that they have been applied in such a manner in the context of accounting for PEAs and PEBs.

The role of personality traits and patterns in environmental behavior has been explored for a few decades (e.g. Arbuthnot 1977); however, the findings accumulated thus far were mainly anecdotal and did not necessarily form a coherent model of how personality may be associated with PEB. Thus, for example, Harland et al. (2007) found that both environmental and personalityrelated cues may trigger PEB, but they did not offer a comprehensive model. Additional research looked for typical personality profiles that are associated with PEB (Markowitz et al. 2012). A relatively recent line of research has attempted to conceptualize the path leading from personality predispositions to PEB. Such studies have suggested that values and attitudes may play a mediating role in the association between personality-level variables and PEB 
(Bamberg and Möser 2007, Hirsh 2010, Vredin Johansson Heldt and Johaet al. 2006). Our study, then, joins this line of investigation, proposing a model in which personality traits at different levels (LOC and FO) work hierarchically to shape attitudinal factors that may in turn shape behavior.

From the demographic characteristics studied, only age was associated positively with both PEAs and PEB. Previous studies were inconclusive about this relationship. Some studies indicated that younger people are more likely to demonstrate concern for the environment (Fransson and Gärling 1999, Van Liere and Dunlap 1980) and PEB (Johnson et al. 2004, Newman and Fernandes 2016); others found no relationship and yet others (Shen and Saijo 2008) reported a negative relationship (i.e., older persons are more engaged in PEB).

Understanding the personal variables that may account for individuals' PEB is vital to enabling optimal educational intervention and education programs in the future, to improve the PEB of the world population. From our findings it emerges that designing a structured environmental educational program that will induce and empower students' LOC and FO regarding the environment may help increase their PEAs and PEB.

\section{Study Limitations and Suggestions for Future Studies}

When considering the study results, the reader may do well to consider the study limitations. First, participants were sampled from a specific country (Israel) whose environmental legislation and culture may differ from those of other samples (however, studies conducted with Israeli samples do not show significant deviations from well-recorded results patterns; for examples, see Carmi 2013, Laor et al. 2018). The sample also showed gender and education biases, but as those typically serve to restrict the range of variance in our measures (see literature review and sample section for more details), we may actually expect the findings in our sample to be even more powerful in the target population. Second, the use of self-report measures, however prevalent and acceptable, might introduce biases recorded in the literature (Donaldson and Grant-Vallone 2002). Finally, the effects found in the study, although statistically significant and potentially theoretically important, are still of mild magnitude and should be considered with care.

Future studies may wish to use actual behavior outcomes as a criterion; use broader, preferably international samples to test the model explored here; and explore whether it indeed applies to diverse settings and target populations.

\section{References}

Ahlin EM, Lobo Antunes MJ (2015) Locus of control orientation: Parents, peers, and place. Journal of Youth and Adolescence 44(9): 1803-1818. doi:10.1007/s10964015-0253-9 
Ajzen I (2002) Perceived behavioral control, self-efficacy, locus of control, and the theory of planned behavior 1. Journal of Applied Social Psychology 32(4): 665683. doi:10.1111/j.1559-1816.2002.tb00236.x

Ajzen I, Fishbein M (2005) The influence of attitudes on behavior. In The handbook of attitudes, D Albarracín, BT Johnson, MP Zanna (eds), 173-221. Mahwah, NJ: Lawrence Erlbaum.

Ajzen I, Madden TJ (1986) Prediction of goal-directed behavior: Attitudes, intentions, and perceived behavioral control. Journal of Experimental Social Psychology 22(5): 453-474. doi:10.1016/0022-1031(86)90045-4.

Albarracín D, Johnson BT, Zanna MP (eds) (2005) The handbook of attitudes. Mahwah, NJ: Lawrence Erlbaum.

Allen JB, Ferrand JL (1999) Environmental locus of control, sympathy, and proenvironmental behavior: A test of Geller's actively caring hypothesis. Environment and Behavior 31(3): 338-353. doi: 10.1177/00139169921972137.

Arbuthnot J (1977) The role of attitudinal and personality variables in the prediction of environmental behavior and knowledge. Environment and Behavior, 9(2): 217-232. doi:10.1177/001391657792004.

Bamberg S, Möser G (2007) Twenty years after Hines, Hungerford, and Tomera: A new meta-analysis of psychosocial determinants of pro-environmental behaviour. Journal of Environmental Psychology 27: 14-25. doi: 10.1016/j. jenvp.2006.12. 002

Beal SJ (2011) The development of future orientation: Underpinnings and related constructs (Doctoral dissertation). Retrieved from http://digitalcommons.unl.edu/ psychdiss/32.

Bruderer Enzler H (2015) Consideration of future consequences as a predictor of environmentally responsible behavior: Evidence from a general population study. Environment and Behavior 47(6): 618-643. doi:10.1177/0013916513512204

Carmi N (2013) Caring about tomorrow: Future orientation, environmental attitudes and behaviors. Environmental Education Research 19(4): 430-444. doi:10.1080/ 13504622.2012 .700697

Cleveland M, Kalamas M, Laroche M (2005) Shades of green: Linking environmental locus of control and pro-environmental behaviors. Journal of Consumer Marketing 22(4): 198-212. doi: 10.1108/07363760510605317.

Corral-Verdugo V, Caso-Niebla J, Tapia-Fonllem C, Frías-Armenta M (2017) Consideration of immediate and future consequences in accepting and responding to anthropogenic climate change. Psychology 8(10): 1519-1531. doi: 10.4236/psych.2017.810101.

Corral-Verdugo V, Fraijo-Sing B, Pinheiro JQ (2006) Sustainable behavior and time perspective: Present, past, and future orientations and their relationship with water conservation behavior. Interamerican Journal of Psychology 40(2): 139147.

Cottrell SP (2003) Influence of sociodemographic and environmental attitudes on general responsible environmental behavior among recreational boaters. Environment and Behavior 35(3): 347-375. doi: 10.1177/0013916503035003 003.

Courtenay-Hall P, Rogers L (2002) Gaps in mind: Problems in environmental knowledge-behaviour modelling research. Environmental Education Research 8(3): 283-297. doi: 10.1080/13504620220145438.

Deci EL, Ryan RM (eds) (2004) Handbook of self-determination research. Rochester, NY: University of Rochester Press. 
Donaldson SI, Grant-Vallone EJ (2002) Understanding self-report bias in organizational behavior research. Journal of Business and Psychology 17(2): 245-260. doi: 10.1023/A:1019637632584.

Fabrigar LR, MacDonald TK, Wegener DT (2005) The structure of attitudes. In The handbook of attitudes, D Albarracín, BT Johnson, MP Zanna (eds), 79-125. Mahwah, NJ: Lawrence Erlbaum.

Fazio RH (1986) How do attitudes guide behavior. In Handbook of motivation and cognition: Foundations of social behavior, RM Sorrentino, ET Higgins (eds), 204-243. New York, NY: Guilford.

Félonneau ML, Becker M (2008) Pro-environmental attitudes and behavior: Revealing perceived social desirability. Revue Internationale de Psychologie Sociale 21(4): 25-53.

Finger M (1994) From knowledge to action? Exploring the relationships between environmental experiences, learning, and behavior. The Journal of Social Issues 50(3): 141-160. doi:10.1111/j.1540-4560.1994.tb02424.x.

Fransson N, Gärling T (1999) Environmental concern: Conceptual definitions, measurement methods, and research findings. Journal of Environmental Psychology 19(4): 369-382. doi:10.1006/jevp.1999.0141.

Gjesme T (1983) Introduction: An inquiry into the concept of future orientation. International Journal of Psychology 18(1-4): 347-350. doi:10.1080/002075983 08247486.

Harland P, Staats H, Wilke HA (2007) Situational and personality factors as direct or personal norm mediated predictors of pro-environmental behavior: Questions derived from norm-activation theory. Basic and Applied Social Psychology 29(4): 323-334. doi: 10.1080/01973530701665058.

Hines JM, Hungerford H R, Tomera AN (1987) Analysis and synthesis of research on responsible environmental behavior: A meta-analysis. The Journal of Environmental Education 18(2): 1-8. doi:10.1080/00958964.1987.9943482

Hirsh JB (2010) Personality and environmental concern. Journal of Environmental Psychology 30(2): 245-248. doi: 10.1016/j.jenvp.2010.01.004

Hungerford HR, Volk TL (1990) Changing learner behavior through environmental education. The Journal of Environmental Education 21(3): 8-21. doi:10.1080/ 00958964.1990 .10753743

Jensen BB (2002) Knowledge, action and pro-environmental behavior. Environmental Education Research 8(3): 325-334. doi:10.1080/13504620220145474

Johnson CY, Bowker JM, Cordell HK (2004) Ethnic variation in environmental belief and behavior: An examination of the new ecological paradigm in a social psychological context. Environment and Behavior 36(2): 157-186. doi:10.1177/ 0013916503251478

Joireman JA, Van Lange PA, Van Vugt M (2004) Who cares about the environmental impact of cars? Those with an eye toward the future. Environment and Behavior 36(2): 187-206. doi: 10.1177/0013916503251476

Kaiser FG, Byrka K (2011) Environmentalism as a trait: Gauging people's prosocial personality in terms of environmental engagement. International Journal of Psychology, 46(1): 71-79. doi:10.1080/00207594.2010.516830

Kluckhohn FR, Strodtbeck FL (1961) Variations in value orientations. New York, NY: HarperCollins.

Kollmuss A, Agyeman J (2002) Mind the gap: Why do people act environmentally and what are the barriers to pro-environmental behavior? Environmental Education Research, 8(3): 239-260. doi:10.1080/13504620220145401 
Laor T, Gan D, Avisar I (2018) Environmental activists in Israel: What motivates them? Ecology \& Environment, April, 2018: 58-64 [in Hebrew].

Lehmann J (1999) Befunde empirischer Forschung zu Umweltbildung und Umweltbewusstsein (Vol. 4). Opladen, Germany: Leske und Budrich.

Levy A, Orion N, Leshem Y (2018) Variables that influence the environmental behavior of adults. Environmental Education Research 24(3): 307-325.

Madden TJ, Ellen PS, Ajzen I (1992) A comparison of the theory of planned behavior and the theory of reasoned action. Personality and Social Psychology Bulletin 18(1): 3-9.

Markowitz EM, Goldberg LR, Ashton MC, Lee K (2012) Profiling the "proenvironmental individual": A personality perspective. Journal of Personality 80(1): 81-111. doi:10.1111/j.1467-6494.2011.00721.x

Masson-Delmotte V, (2018) Global warming of $1.5^{\circ} \mathrm{C}$ : An IPCC special report on the impacts of global warming of $1.5^{\circ} \mathrm{C}$ above pre-industrial levels and related global greenhouse gas emission pathways, in the context of strengthening the global response to the threat of climate change, sustainable development, and efforts to eradicate poverty. Geneva, Switzerland: Intergovernmental Panel on Climate Change. Retrieved from https://bit.ly/2vI31yZ.

McCarty JA, Shrum LJ (2001) The influence of individualism, collectivism, and locus of control on environmental beliefs and behavior. Journal of Public Policy \& Marketing 20(1): 93-104. doi:10.1509/jppm.20.1.93.17291.

Milfont TL (2007) Psychology of environmental attitudes: A cross-cultural study of their content and structure (Doctoral dissertation, ResearchSpace@ Auckland).

Milfont TL, Duckitt J (2010) The environmental attitudes inventory: A valid and reliable measure to assess the structure of environmental attitudes. Journal of Environmental Psychology 30(1): 80-94. doi:10.1016/j.jenvp.2009.09.001.

Milfont TL, Wilson J, Diniz P (2012) Time perspective and environmental engagement: A meta-analysis. International Journal of Psychology 47(5): 325334. doi:10.1080/00207594.2011.647029

Newman TP, Fernandes R (2016) A re-assessment of factors associated with environmental concern and behavior using the 2010 General Social Survey. Environmental Education Research 22(2): 153-175. doi:10.1080/13504622.201 4.999227

Nunez C (2019) Is global warming real? National Geographic, July. Retrieved from https://on.natgeo.com/2QFQP90.

Pe'er S, Goldman D, Yavetz B (2007) Environmental literacy in teacher training: Attitudes, knowledge, and environmental behavior of beginning students. The Journal of Environmental Education 39(1): 45-59. doi:10.3200/JOEE.39.1.4559.

Pettijohn T (2004) Locus of Control instrument. University of Virginia: Darden School of Business.

Pettijohn TF, Pettijohn TF, Sacco Jr DF (2005) A locus of control measure as a teaching demonstration. Psychological reports 97(2): 666-667.

Pettus AM, Giles MB (1987) Personality characteristics and environmental attitudes. Population and Environment 9(3): 127-137. doi: 10.1007/BF01259303

Qian C, Yu K, Gao J (2019) Understanding environmental attitude and willingness to pay with an objective measure of attitude strength. Environment and Behavior. doi:10.1177/0013916519855140.

Rajecki DW (1982) Attitudes, themes and advances ( $1^{\text {st }}$ ed). Sunderland, MA: Sinauer Associates. 
Redondo I, Puelles M (2017) The connection between environmental attitudebehavior gap and other individual inconsistencies: A call for strengthening selfcontrol. International Research in Geographical and Environmental Education, 26(2): 107-120. doi:10.1080/10382046.2016.1235361.

Seginer R (2009) Future orientation: Developmental and ecological perspectives. New York, NY: Springer Science \& Business Media.

Shen J, Saijo T (2008) Reexamining the relations between socio-demographic characteristics and individual environmental concern: Evidence from Shanghai data. Journal of Environmental Psychology 28(1): 42-50. doi: 10.1016/j. jenvp. 2007.10.003.

Stern PC (2000) New environmental theories: Toward a coherent theory of environmentally significant behavior. Journal of Social Issues 56(3): 407-424. doi: 10.1111/0022-4537.00175.

Strathman A, Gleicher F, Boninger DS, Edwards CS (1994) The consideration of future consequences: Weighing immediate and distant outcomes of behavior. Journal of Personality and Social Psychology 66(4): 742-752. doi:10.1037/0022 $-3514.66 .4 .742$

Trivedi RH, Patel JD, Savalia JR (2015) Pro-environmental behavior, locus of control and willingness to pay for environmental friendly products. Marketing Intelligence \& Planning 33(1): 67-89. doi:10.1108/MIP-03-2012-0028

Van Liere KD, Dunlap RE (1980) The social bases of environmental concern: A review of hypotheses, explanations and empirical evidence. Public Opinion Quarterly 44(2): 181-197. doi: 10.1086/268583

Volcovici V (2019) Americans demand climate action (as long as it doesn't cost much): Reuters poll. Reuters, June 26. Retrieved from https://reut.rs/2UaoCcA.

Vredin Johansson M, Heldt T, Johansson P (2006) The effects of attitudes and personality traits on mode choice. Transportation Research Part A: Policy and Practice 40(6): 507-525. doi:10.1016/j.tra.2005.09.001

Wootton JT (1994) Predicting direct and indirect effects: An integrated approach using experiments and path analysis. Ecology 75(1): 151-165. doi: 10.2307/19 39391.

Yavetz B, Goldman D, Pe'er S (2011) Characterization of environmental literacy of teaching students toward graduation: Implications for teacher education in Israel. Dapim 52: 137-183 [in Hebrew].

Zelezny LC, Chua PP, Aldrich C (2000) New ways of thinking about environmentalism: Elaborating on gender differences in environmentalism. Journal of Social issues 56(3): 443-457.

Zimbardo PG, Boyd JN (1999) Putting time in perspective: A valid, reliable individual-differences metric. Journal of Personality and Social Psychology 77(6): 1271-1288. doi:10.1037/0022-3514.77.6.1271. 